(C) American Dairy Science Association, 2005.

\title{
Genetic Association Between Susceptibility to Clinical Mastitis and Protein Yield in Norwegian Dairy Cattle
}

\author{
B. Heringstad, ${ }^{1,2}$ Y. M. Chang, ${ }^{3}$ D. Gianola, ${ }^{1,3}$ and G. Klemetsdal ${ }^{1}$ \\ ${ }^{1}$ Department of Animal and Aquacultural Sciences, Agricultural University of Norway, \\ P.O. Box 5003, N-1432 Ås, Norway \\ ${ }^{2}$ GENO Breeding and Al Association, P.O. Box 5003, N-1432 Ås, Norway \\ ${ }^{3}$ Department of Dairy Science, University of Wisconsin, Madison 53706
}

\begin{abstract}
The objective of this study was to examine associations between susceptibility to clinical mastitis and protein yield in first-lactation Norwegian Dairy Cattle (NRF) cows. Records from 372,227 first-lactation daughters of $2411 \mathrm{NRF}$ sires were analyzed bivariately, using a threshold-liability model for clinical mastitis and a linear Gaussian model for 305-d protein yield. The mean (SD) of the posterior distribution of heritability was 0.08 (0.004) for susceptibility to clinical mastitis and $0.19(0.007)$ for $305-d$ protein yield. The posterior mean (SD) of the genetic correlation between susceptibility to clinical mastitis and 305-d protein yield was 0.43 (0.03). Posterior means of the correlations between herd-5-yr effects, and between model residuals were 0.19 and -0.008 , respectively. Corresponding estimates of genetic, herd-5-yr, and residual correlations from a bivariate linear model analysis were $0.42,0.18$, and -0.008 , respectively. An antagonistic genetic relationship between clinical mastitis and protein yield was corroborated.
\end{abstract}

(Key words: Bayesian methods, clinical mastitis, genetic correlation, protein yield)

Abbreviation key: $\mathbf{C M}=$ clinical mastitis, $\mathbf{N R F}=$ Norwegian Dairy Cattle, $\mathbf{P Y}=$ protein yield.

\section{INTRODUCTION}

Genetic relationships between milk yield and many health traits in dairy cows are antagonistic. Thus, single trait selection for increased milk yield is expected to result in a genetic deterioration of health status of animals. Estimates of the genetic correlation between clinical mastitis (CM) and milk yield range from 0.21 to 0.55 (Simianer et al., 1991; Pösö and Mäntysaari, 1996; Luttinen and Juga, 1997; Nielsen et al., 1997;

Received October 19, 2004.

Accepted December 6, 2004.

Corresponding author: Bjørg Heringstad; e-mail: bjorg.heringstad @umb.no.
Pryce et al., 1997; Heringstad et al., 1999; Lund et al., 1999; Rupp and Boichard, 1999; Hansen et al., 2002; Carlén et al., 2004). Most of these estimates were obtained using linear models, disregarding the fact that the scoring of CM is categorical, and a liability-threshold model (Gianola and Foulley, 1983) would be more appropriate. In theory, estimates of genetic correlation between a continuous trait and the underlying susceptibility for a binary trait can be obtained directly from a bivariate linear model analysis, at least in pure random effects models (Gianola, 1982). However, a simulation study indicated that linear sire models under certain conditions (low heritability and low incidence of the binary trait) produce estimates that understate the true value of the genetic correlation (Gates et al., 1999).

Our main objective was to examine associations between liability to CM and protein yield (PY) in firstlactation Norwegian Dairy Cattle (NRF) cows, based on a large data set and using the most appropriate statistical methods available. A bivariate analysis with a threshold model for CM and a Gaussian model for PY were used for inferring correlations. Another objective was to compare estimates of genetic correlation from this analysis with those obtained with linear models.

\section{MATERIALS AND METHODS}

\section{Data}

The data set consisted of records from first-lactation daughters of $2411 \mathrm{NRF}$ sires, progeny-tested from 1978 through 1998. Only first-crop daughters (i.e., when the difference between the birth year of a daughter and the birth year of its sire was $<6 \mathrm{yr}$ ) were included. Records of daughters of bulls with fewer than 20 daughters were excluded. The data were restricted further to include only cows in a herd-5-yr class with at least 10 firstlactation cows.

Mastitis was scored as a binary trait, based on whether a cow had at least one veterinary treatment of $\mathrm{CM}$ in the interval from $30 \mathrm{~d}$ before to $300 \mathrm{~d}$ after first calving. The milk production trait was 305-d PY in first lactation. Only cows that completed a 305-d 
Table 1. Summary statistics of the data used for analysis of clinical mastitis and 305-d protein yield (PY).

\begin{tabular}{lr}
\hline Item & \\
\hline Records, no. & 372,227 \\
Sires, no. & 2411 \\
Daughters per sire, mean no. & 154 \\
Herd-5-yr classes, no. & 25,033 \\
Records per herd-5-yr class, mean no. & 14.9 \\
Mean 305-d PY, kg & 173.6 \\
Mastitis frequency, ${ }^{1} \%$ & 20.6 \\
\hline
\end{tabular}

${ }^{1}$ Mastitis frequency = percentage of cows with at least one record of veterinary treatment of clinical mastitis in the period from $30 \mathrm{~d}$ prepartum to $300 \mathrm{~d}$ after first calving.

lactation were considered for 305-d PY. The edited data set used for analysis had 372,227 cows, all of which had mastitis data, and 269,549 of which had 305-d PY data. Descriptive statistics for the data set are given in Table 1. The sire pedigree file had 2726 males, including the 2411 sires with daughters in the data set.

\section{Model}

A bivariate statistical model was fitted, with $\mathrm{CM}$ as binary (threshold) and 305-d PY as a Gaussian trait. A threshold-liability model (e.g., Gianola, 1982) was used for analysis of the binary CM data. The threshold model postulates an underlying continuous variable, liability $(\lambda)$, such that an observed binary response takes value 1 if $\lambda$ is larger than a fixed threshold $(\tau)$ and 0 otherwise. With binary data, the $\tau$ and the residual variance are not identifiable; these parameters were therefore set to 0 and 1 , respectively. Here, it was assumed that susceptibility to CM and 305-d PY were jointly Gaussian. This model was developed by Foulley et al. (1983).

The same linear model was used for susceptibility to $\mathrm{CM}$ and 305-d PY. In matrix notation, the model fitted can be written as:

$$
\mathbf{y}=\mathbf{X} \boldsymbol{\beta}+\mathbf{Z}_{\mathbf{h}} \mathbf{h}+\mathbf{Z}_{\mathbf{s}} \mathbf{s}+\mathbf{e}
$$

where $\mathbf{y}$ is a vector of unobserved susceptibilities for $\mathrm{CM}$ and observed records of 305-d PY; $\boldsymbol{\beta}$ is a vector of systematic effects; $\mathbf{h}$ is a vector of herd-5-yr of calving effects; $\mathbf{s}$ is a vector of sire transmitting abilities; $\mathbf{e}$ is the vector of residual effects; and $\mathbf{X}, \mathbf{Z}_{\mathbf{h}}$, and $\mathbf{Z}_{\mathbf{s}}$ are the corresponding incidence matrices.

The $\beta$ vector included age at first calving and month $\times$ year of first-calving effects. Age at first calving had 15 levels: $<20$ mo was the first class, $>32$ mo was the last class, and other classes were in single months. Month $\times$ year of first-calving effects had 240 levels, from September 1978 through August 1998. The effect of herd-5-yr of first calving had 25,033 levels. Residuals were assumed to follow the normal distribution $\mathbf{e} \sim N\left(\mathbf{0}, \mathbf{R}_{\mathbf{0}} \otimes \mathbf{I}\right)$ where $\mathbf{R}_{\mathbf{0}}=\left[\begin{array}{cc}1 & \sigma_{e 1 e 2} \\ \sigma_{e 1 e 2} & \sigma_{e 2}^{2}\end{array}\right]$ is the residual (co)variance matrix and $\mathbf{I}$ is an identity matrix. Residuals were assumed independent between cows, and correlated between records of the same cow. The residual variance for the susceptibility to CM, was as mentioned above set equal to 1 , to attain parameter identification. Thus, the residual correlation between CM and 305-d PY was $\sigma_{e 1 e 2} / \sigma_{e 2}$.

\section{Bayesian Analysis}

A Bayesian approach using Markov chain Monte Carlo (MCMC) methods (e.g., Sorensen and Gianola, 2002), as applied by Heringstad et al. (2003b), was implemented. The form of the Bayesian model follows.

Prior distributions. Independent proper uniform priors were assumed for each of the p elements of $\beta$ :

$$
\beta_{i} \sim U\left(\beta_{\min }, \beta_{\max }\right), i=1,2, \ldots, p .
$$

Hyper-parameters values were $\beta_{\min }=-9999$ and $\beta_{\max }=9999$. The average number of records per herd5 -yr class was small, so to alleviate the well-known extreme category problem of the threshold model, the herd-5-yr effects were assigned a multivariate normal prior distribution with unknown variance:

$$
\mathbf{h} \sim N\left(\mathbf{0}, \mathbf{H}_{\mathbf{0}} \otimes \mathbf{I}\right)
$$

where $\mathbf{H}_{\mathbf{0}}=\left[\begin{array}{cc}\sigma_{h 1}^{2} & \sigma_{h 1 h 2} \\ \sigma_{h 1 h 2} & \sigma_{h 2}^{2}\end{array}\right]$ is the (co)variance matrix between herd-5-yr effects and $\mathbf{I}$ is an identity matrix with order equal to the number of herd-5-yr effects. The following multivariate normal prior distribution was adopted for the sire transmitting abilities:

$$
\mathbf{s} \sim N\left(\mathbf{0}, \mathbf{G}_{\mathbf{0}} \otimes \mathbf{A}\right)
$$

where $\mathbf{G}_{\mathbf{0}}=\left[\begin{array}{cc}\sigma_{s 1}^{2} & \sigma_{s 1 s 2} \\ \sigma_{s 1 s 2} & \sigma_{s 2}^{2}\end{array}\right]$ is the (co)variance matrix between sire transmitting abilities, and $\mathbf{A}$ is the known matrix of additive relationships between sires. Inverse Wishart prior distributions were used for the matrices $\mathbf{H}_{\mathbf{0}}$ and $\mathbf{G}_{\mathbf{0}}$ :

$$
\begin{aligned}
& \mathbf{H}_{\mathbf{0}} \sim I W\left(\nu_{h}, \mathbf{V}_{h}\right) \\
& \mathbf{G}_{\mathbf{0}} \sim I W\left(\nu_{g}, \mathbf{V}_{g}\right)
\end{aligned}
$$


Table 2. Means and standard deviations (SD) of posterior distributions of sire, herd-5-yr, and residual (co)variances, heritabilities, and genetic, herd-5-yr, and residual correlations: bivariate analysis of susceptibility to clinical mastitis (CM) and 305-d protein yield (PY).

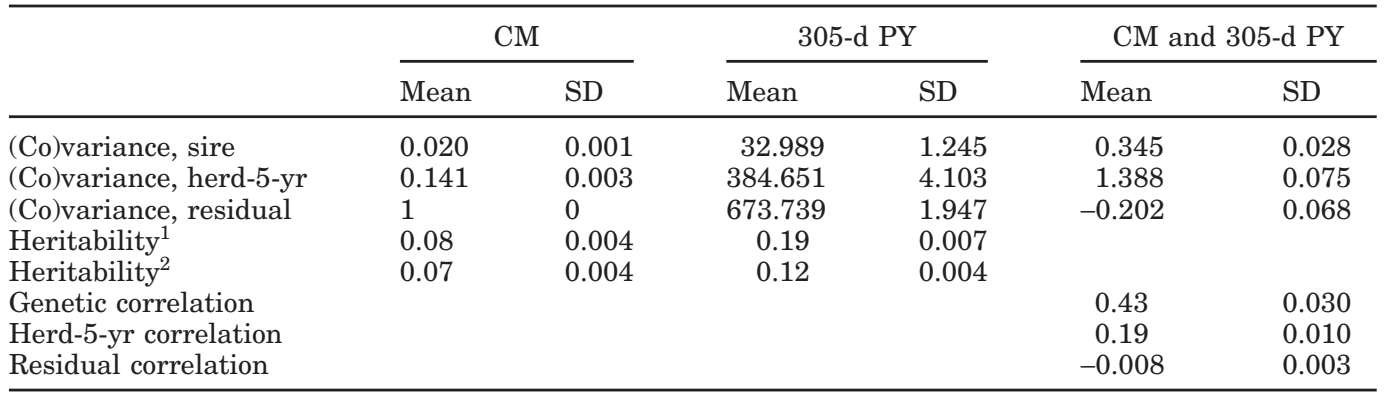

${ }^{1} \mathrm{~h}^{2}=4 \sigma_{\mathrm{s}}^{2} /\left(\sigma_{\mathrm{s}}^{2}+\sigma_{\mathrm{e}}^{2}\right)$, where $\sigma_{\mathrm{s}}^{2}=$ sire variance and $\sigma_{\mathrm{e}}^{2}=$ residual variance.

${ }^{2} \mathrm{~h}^{2}=4 \sigma_{\mathrm{s}}^{2} /\left(\sigma_{\mathrm{s}}^{2}+\sigma_{\mathrm{h}}^{2}+\sigma_{\mathrm{e}}^{2}\right)$, where $\sigma_{\mathrm{s}}^{2}=$ sire variance, $\sigma_{\mathrm{h}}^{2}=$ herd variance, and $\sigma_{\mathrm{e}}^{2}=$ residual variance.

where $\nu_{\mathrm{h}}=\nu_{\mathrm{g}}=2$ are the degrees of freedom parameters, and $\mathbf{V}_{\mathbf{h}}=\mathbf{V}_{g}=\left[\begin{array}{cc}0.1 & 0 \\ 0 & 0.1\end{array}\right]$ are scale matrices. A scaled inverse $\chi^{2}$ prior distribution was assigned to the residual variance of 305-d PY $\left(\sigma_{e 2}^{2}\right)$, and a bounded uniform prior was used for the residual covariance between 305d PY and $\mathrm{CM}\left(\sigma_{e 12}\right)$ :

$$
\begin{gathered}
\sigma_{e 2}^{2} \sim \boldsymbol{\nu}_{e 2} S_{e 2}^{2} \chi_{\nu_{e 2}}^{-1} \\
\sigma_{e 1 e 2} \mid \sigma_{e 2}^{2} \sim U\left(-\sqrt{\sigma_{e 2}^{2}}, \sqrt{\sigma_{e 2}^{2}}\right)
\end{gathered}
$$

with $\nu_{e 2}=2$ and $S_{e 2}^{2}=4$. The joint prior density of all unknown parameters was assumed to have the form:

$$
\begin{gathered}
p\left(\boldsymbol{\beta}, \mathbf{h}, \mathbf{s}, \mathbf{H}_{\mathbf{0}}, \mathbf{G}_{\mathbf{0}}, \sigma_{e 2}^{2}, \sigma_{e 12} \mid \text { hyperparameters }\right) \\
\propto p(\boldsymbol{\beta}) p\left(\mathbf{h} \mid \mathbf{H}_{\mathbf{0}}\right) p\left(\mathbf{s} \mid \mathbf{G}_{\mathbf{0}}\right) p\left(\mathbf{H}_{\mathbf{0}} \mid \boldsymbol{\nu}_{h}, \mathbf{V}_{\mathbf{h}}\right) p\left(\mathbf{G}_{\mathbf{0}} \mid \boldsymbol{\nu}_{g}, \mathbf{V}_{\mathbf{g}}\right) \\
p\left(\sigma_{e 2}^{2} \mid \boldsymbol{\nu}_{e 2}, S_{e 2}^{2}\right) p\left(\sigma_{e 12} \mid \sigma_{e 2}^{2}\right)
\end{gathered}
$$

so all parameters were assumed independent, a priori, with the exception of $\mathbf{h}, \mathbf{s}$ and $\sigma_{e 12}$, whose distributions depended on $\mathbf{H}_{\mathbf{0}}, \mathbf{G}_{\mathbf{0}}$ and $\sigma_{e 2}^{2}$, respectively.

Posterior distributions. The joint posterior density is proportional to the product of the joint prior density and the conditional density of the observations, given the parameters. Draws from the joint posterior distributions of all the parameters were obtained using a Gibbs sampler after augmenting the posterior distribution with the unobservable liabilities (Sorensen et al., 1995).

Convergence diagnostics. Length of burn-in and of sampling period, and a measure of mixing rate were obtained following Raftery and Lewis (1992). Based on the diagnostics used and on visual inspection of trace plots, a chain of 50,000 iterations was run, after a "burn- in" of 10,000 rounds. All post burn-in samples were kept for inference of posterior features.

\section{Linear Model Analysis}

For comparison purposes, the same data set was analyzed using a bivariate linear sire model, ignoring the binary nature of CM. The explanatory structure was as given above, except that here, $\mathbf{y}$ is a vector of observations of CM ( 0 or 1 ) and of records of 305-d PY. (Co)variance components were estimated using the AI-REML procedure in the DMU package (Madsen and Jensen, 2002).

\section{RESULTS AND DISCUSSION}

Posterior means and standard deviations (SD) of (co)variance components and of corresponding heritabilities and correlations from the bivariate analysis of susceptibility to CM and 305-d PY are given in Table 2. The posterior distributions of all parameters were sharp and symmetric, as illustrated in Figures 1 and 2 , where posterior distributions of heritabilities of susceptibility to CM and 305-d PY, respectively, are given.

The posterior mean (SD) of heritability of susceptibility to $\mathrm{CM}$ was 0.08 (0.004) (Table 2). This point estimate is in agreement with published results from analyses of Nordic mastitis data using threshold models, where estimates have ranged from 0.06 to 0.12 (Simianer et al., 1991; Lund et al., 1999; Heringstad et al., 2001; Chang et al., 2002; Heringstad et al., 2003a).

The posterior mean (SD) of heritability of 305-d PY, at 0.19 (0.007), was in agreement with previous estimates from Norwegian data (Heringstad et al., 1999; 2003c; Andersen-Ranberg et al., 2005), but it is lower than in studies in Denmark and Finland (e.g., Pösö and Mäntysaari, 1996; Lund et al., 1999; Hansen et al., 2002). 


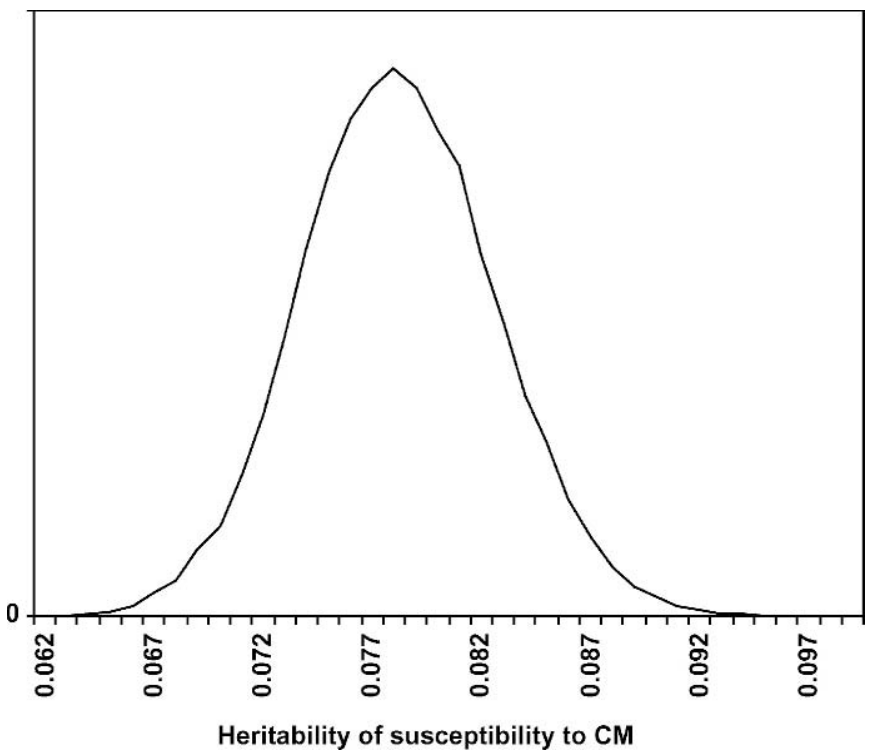

Figure 1. Posterior distribution of heritability $\left[h^{2}=4 \sigma_{\mathrm{s}}^{2} /\left(\sigma_{\mathrm{s}}^{2}+1\right)\right]$ of susceptibility to clinical mastitis (CM).

As shown in Figure 3, the posterior distribution of the genetic correlation between susceptibility to $\mathrm{CM}$ and 305-d PY was sharp and symmetric, with mean and SD of 0.43 and 0.03 , respectively (Table 2). This estimate, in agreement with literature values, corroborates the antagonistic genetic relationship between resistance to mastitis and milk production. In a review, Heringstad et al. (2000) reported estimates of the ge-



Figure 2. Posterior distribution of heritability $\left[\mathrm{h}^{2}=4 \sigma_{\mathrm{s}}^{2} /\left(\sigma_{\mathrm{s}}^{2}+\sigma_{\mathrm{e}}^{2}\right)\right]$ of 305-d protein yield (PY).

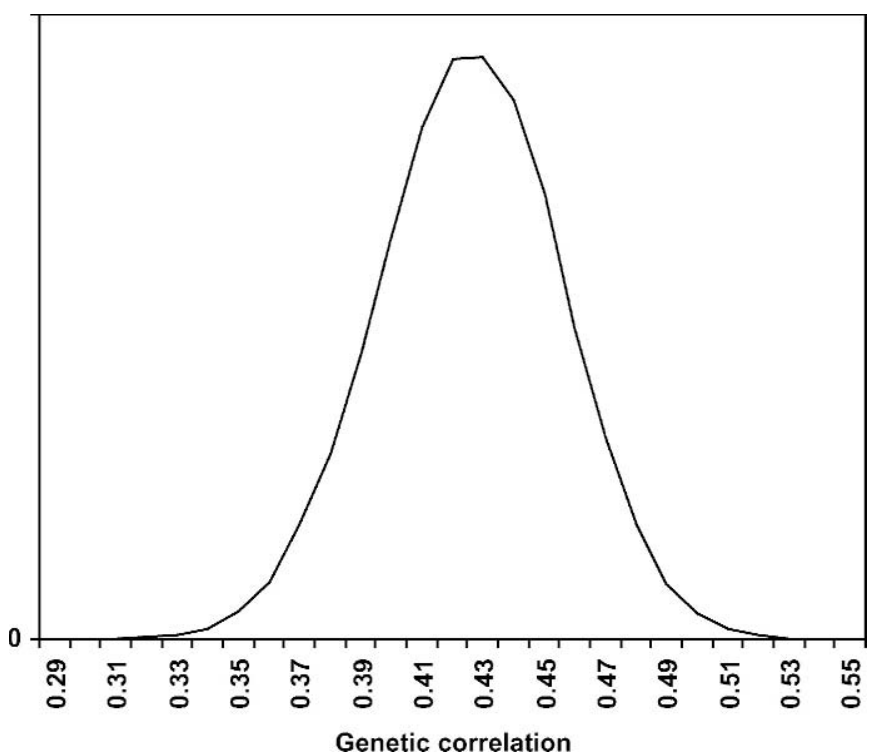

Figure 3. Posterior distribution of the genetic correlation between susceptibility to clinical mastitis and 305-d protein yield.

netic correlation between mastitis susceptibility and milk yield ranging between 0.24 and 0.55 , with an average of 0.43 .

The correlation between herd-5-yr effects was positive, with posterior mean and SD of 0.19 and 0.01 , respectively (Table 2). This result suggests that herds with higher 305-d PY tend to have higher susceptibility to CM. The residual correlation between the 2 traits was nil, with posterior mean (SD) -0.008 (0.003) (Table 2).

Parameter estimates from the linear model analysis are given in Table 3. Estimates of heritability of 305-d PY, as well as of genetic, herd-5-yr, and residual correlations were approximately the same as in the bivariate threshold-linear model (Table 2). Although simulation studies have shown that estimates from linear models may understate the genetic correlation between a binary and a continuous trait (e.g., Gates et al., 1999), no evidence for this was observed in our study. One should note that the mean frequency of the binary trait $\mathrm{CM}$ in the analyzed data was $20.6 \%$ (Table 1 ). This fact may be one reason why correlation estimates were the same in the 2 models, inasmuch as differences between threshold and linear models tend to increase as the ratio of observations in each class becomes more disparate (e.g., fewer than $10 \%$ in a given category).

The heritability of susceptibility to CM (threshold model, Table 2) was, as expected, higher than the heritability of CM from the linear model (Table 3). In a review, Heringstad et al. (2000) found that most estimates of heritability of $\mathrm{CM}$ from linear models were between 0.02 and 0.03 , whereas heritability of suscepti- 
Table 3. Restricted maximum likelihood (REML) estimates and standard errors (SE) ${ }^{3}$ of sire, herd-5-yr, and residual (co)variances, heritabilities, and genetic, herd-5-yr, and residual correlations from the linear model analysis of clinical mastitis (CM) and 305-d protein yield (PY).

\begin{tabular}{|c|c|c|c|c|c|c|}
\hline & \multicolumn{2}{|c|}{$\mathrm{CM}$} & \multicolumn{2}{|c|}{ 305-d PY } & \multicolumn{2}{|c|}{ CM and 305-d PY } \\
\hline & Estimate & $\mathrm{SE}$ & Estimate & SE & Estimate & SE \\
\hline (Co)variance, sire & 0.0014 & 0.0001 & 33.09 & 1.24 & 0.0898 & 0.0073 \\
\hline (Co)variance, herd-5-yr & 0.0100 & 0.0002 & 384.74 & 4.08 & 0.3598 & 0.0196 \\
\hline (Co)variance, residual & 0.1510 & 0.0004 & 673.73 & 1.94 & -0.0819 & 0.0208 \\
\hline Heritability $^{1}$ & 0.036 & $\ldots$ & 0.187 & $\ldots$ & $\ldots$ & $\ldots$ \\
\hline Heritability $^{2}$ & 0.034 & $\ldots$ & 0.121 & $\ldots$ & $\ldots$ & $\ldots$ \\
\hline Genetic correlation & $\ldots$ & $\ldots$ & $\ldots$ & $\ldots$ & 0.422 & 0.030 \\
\hline Herd-5-year correlation & $\ldots$ & $\ldots$ & $\ldots$ & $\ldots$ & 0.184 & 0.010 \\
\hline Residual correlation & $\ldots$ & $\ldots$ & $\ldots$ & $\ldots$ & -0.008 & 0.002 \\
\hline
\end{tabular}

${ }^{1} \mathrm{~h}^{2}=4 \sigma_{\mathrm{s}}^{2} /\left(\sigma_{\mathrm{s}}^{2}+\sigma_{\mathrm{e}}^{2}\right)$, where $\sigma_{\mathrm{s}}^{2}=$ sire variance and $\sigma_{\mathrm{e}}^{2}=$ residual variance.

${ }^{2} \mathrm{~h}^{2}=4 \sigma_{\mathrm{s}}^{2} /\left(\sigma_{\mathrm{s}}^{2}+\sigma_{\mathrm{h}}^{2}+\sigma_{\mathrm{e}}^{2}\right)$, where $\sigma_{\mathrm{s}}^{2}=$ sire variance, $\sigma_{\mathrm{h}}^{2}=$ herd variance, and $\sigma_{\mathrm{e}}^{2}=$ residual variance.

${ }^{3}$ Standard errors are asymptotic SE based on the AI-information matrix.

bility to CM from threshold models ranged from 0.06 to 0.12 .

The unfavorable genetic correlation between $\mathrm{CM}$ and 305-d PY implies that if mastitis is ignored in a breeding program, selection for increased milk production will result in an increase in CM. Results from 2 Norwegian selection experiments (Heringstad et al., 2003c) have demonstrated the effect of direct and indirect selection on CM. Unfavorable correlated selection response in $\mathrm{CM}$ was observed in the line selected for increased milk production. On the other hand, the estimated genetic trend in a line selected for low CM indicated that a sizable direct genetic response could be achieved. Results for the entire NRF population (Heringstad et al., 2003c) illustrate that production and animal health can be increased by genetic selection simultaneously, provided the breeding objective is defined properly, progeny testing is based on large daughter groups, and the trait is given sufficient weight in selection.

\section{CONCLUSIONS}

The present study corroborated the existence of an antagonistic genetic relationship between clinical mastitis and protein yield. Correlation estimates obtained from threshold-linear and bivariate linear models were similar, and there was no evidence of underestimation of genetic correlations in the linear model analysis. Heritability of susceptibility to CM was considerably higher than heritability of $\mathrm{CM}$ obtained in the linear model analysis.

\section{ACKNOWLEDGMENTS}

Access to the data was given by the Norwegian Dairy Herd Recording System and the Norwegian Cattle Health Service in agreement number 011.2000 of
12.10.2000. GENO Breeding and AI Association is acknowledged for providing pedigree information on sires. This work is part of the "Healthy Cow" project financed by the Research Council of Norway. Support was also received from the Babcock Institute for International Dairy Research and Development, University of Wisconsin, Madison, and by grants NRICGP/USDA 200335205-12833 and NSF DEB-0089742.

\section{REFERENCES}

Andersen-Ranberg, I. M., G. Klemetsdal, B. Heringstad, and T. Steine. 2005. Heritabilities, genetic correlations, and genetic change for female fertility and protein yield in Norwegian Dairy Cattle. J. Dairy Sci. 88:348-355.

Carlén, E., E. Strandberg, and A. Roth. 2004. Genetic parameters for clinical mastitis, somatic cell score, and production in the first three lactations of Swedish Holstein Cows. J. Dairy Sci. 87:3062-3070.

Chang, Y. M., D. Gianola, B. Heringstad, and G. Klemetsdal. 2002. Correlations between clinical mastitis in different periods of first lactation Norwegian Cattle using a multivariate threshold model. Pages 177-192 in Case Studies in Bayesian Statistics, Vol 6. C. Gatsonis, A. Carriquiry, A. Gelman, D. Higdon, R. Kass, D. Pauler, and I. Verdinelli, ed. Springer-Verlag, New York, NY.

Foulley, J. L., D. Gianola, and R. Thompson. 1983. Prediction of genetic merit from data on binary and quantitative variates with an application to calving difficulty, birth weight, and pelvic opening. Genet. Sel. Evol. 15:401-424.

Gates, P., K. Johansson, and B. Danell. 1999. "Quasi-REML" correlation estimates between production and health traits in the presence of selection and confounding: A simulation study. J. Anim. Sci. 77:558-568.

Gianola, D. 1982. Theory and analysis of threshold characters. J. Anim. Sci. 54:1079-1096.

Gianola, D., and J. L. Foulley. 1983. Sire evaluation for ordered categorical data with a threshold model. Genet. Sel. Evol. 15:201-224

Hansen, M., M. S. Lund, M. K. Sørensen, and L. G. Christensen. 2002. Genetic parameters of dairy character, protein yield, clinical mastitis, and other diseases in Danish Holstein cattle. J. Dairy Sci. 85:445-452.

Heringstad, B., G. Klemetsdal, and J. Ruane. 1999. Clinical mastitis in Norwegian Cattle: Frequency, variance components and genetic correlation with protein yield. J. Dairy Sci. 82:1325-1330. 
Heringstad, B., G. Klemetsdal, and J. Ruane. 2000. Selection for mastitis resistance in dairy cattle - A review with focus on the situation in the Nordic countries. Livest. Prod. Sci. 64:95-106.

Heringstad, B., G. Klemetsdal, and T. Steine. 2003c. Selection responses for clinical mastitis and protein yield in two Norwegian dairy cattle selection experiments. J. Dairy Sci. 86:2990-2999.

Heringstad, B., R. Rekaya, D. Gianola, G. Klemetsdal, and K. A. Weigel. 2001. Bayesian analysis of liability to clinical mastitis in Norwegian Cattle with a threshold model: Effects of data sampling method and model specification. J. Dairy Sci. 84:2337-2346.

Heringstad, B., R. Rekaya, D. Gianola, G. Klemetsdal, and K. A. Weigel. 2003a. Genetic change for clinical mastitis in Norwegian Cattle: A threshold model analysis. J. Dairy Sci. 86:369-375.

Heringstad, B., R. Rekaya, D. Gianola, G. Klemetsdal, and K. A. Weigel. 2003b. Bivariate analysis of liability to clinical mastitis and to culling in first-lactation cows. J. Dairy Sci. 86:653-660.

Lund, M. S., J. Jensen, and P. H. Petersen. 1999. Estimation of genetic and phenotypic parameters for clinical mastitis, somatic cell deviance, and protein yield in dairy cattle using Gibbs sampling. J. Dairy Sci. 82:1045-1051.

Luttinen, A., and J. Juga. 1997. Genetic relationships between milk yield, somatic cell count, mastitis, milkability and leakage in Finnish dairy cattle. Interbull Bull. 15:78-83.

Madsen, P., and J. Jensen. 2002. A user's guide to DMU. A package for analysing multivariate mixed models. Version 6 , release 4.3 Danish Institute for Agricultural Sciences, Foulum, Denmark.
Nielsen, U. S., G. A. Pedersen, and J. Jensen. 1997. Genetic correlations among health traits in different lactations. Interbull Bull. 15:68-77.

Pösö, J., and E. A. Mäntysaari. 1996. Relationships between clinical mastitis, somatic cell score, and production in the first three lactations of Finnish Ayrshire. J. Dairy Sci. 79:1284-1291.

Pryce, J. E., R. F. Veerkamp, R. J. Esslemont, M. A. Kossaibati, and G. Simm. 1997. Genetic associations amongst health and fertility traits for two UK recording schemes. Interbull Bull. 15:92-97.

Raftery, A. L., and S. Lewis. 1992. How many iterations in the Gibbs sampler? Pages 763-774 in Bayesian Statistics 4. J. M. Bernando, J. O. Berger, A. P. Dawid, and A. F. M. Smith, ed. Oxford University Press, Oxford, UK.

Rupp, R., and D. Boichard. 1999. Genetic parameters for clinical mastitis, somatic cell score, production, udder type traits, and milking ease in first-lactation Holsteins. J. Dairy Sci. 82:21982204.

Simianer, H., H. Solbu, and L. R. Schaeffer. 1991. Estimated genetic correlations between disease and yield traits in dairy cattle. J. Dairy Sci. 74:4359-4365.

Sorensen, D., and D. Gianola. 2002. Likelihood, Bayesian, and MCMC methods in quantitative genetics. Springer-Verlag, New York, NY.

Sorensen, D. A., S. Andersen, D. Gianola, and I. Korsgaard. 1995. Bayesian inference in threshold models using Gibbs sampling. Genet. Sel. Evol. 27:229-249. 